\title{
PEMIKIRAN MOHAMMAD ILYAS TENTANG PENYATUAN KALENDER ISLAM INTERNASIONAL
}

\author{
Rupi'i Amri \\ Fakultas Syari'ah dan Hukum UIN Walisongo Semarang \\ Jl. Prof. Dr. Hamka Kampus III Ngaliyan Semarang 50185 \\ Telp. 0247601291, HP. 08122512113 \\ E-Mail: rupiiamri@gmail.com
}

\begin{abstract}
The object of this study is Mohammad Ilyas's concept of the unification of International Islamic calendar. The Method of analysis is descriptif-analysis. The results of this research show that Mohammad Ilyas's concept of the unification of International Islamic Calendar based on the hisab of the crescent visibility and the International Lunar Date Line (ILDL). The Ilyas's criteria of the crescent visibility use two parameter, i.e. geocentric relative altitude and relatif azimut. The application of Mohammad Ilyas's concept of the crescent visibility as the unification of International Islamic calendar can't accepted by Indonesia Moslem. This problem is caused by the difference criteria between Indonesia Moslem (Indonesia Religious Affair) of the crescent visibility and Ilyas. Ilyas's concept of International Lunar Date Line is always change every month. This condition is cause the difference in the beginning of the day on the first month in the region of the country.
\end{abstract}

Keyword: unification, International Islamic calendar, crescent visibility.

Abstrak: Umat Islam sampai saat ini masih berbeda-beda dalam menentukan awal bulan kamariah. Perbedaan ini mengakibatkan perbedaan pula dalam memulai peribadatan-peribadatan tertentu, yang paling menonjol ialah perbedaan dalam memulai puasa Ramadan, Idul Fitri, dan Idul Adha. Perbedaan penetapan awal bulan tersebut membuat para tokoh falak dan astronomi bekerja keras untuk memikirkan upaya penyatuan kalender Islam, baik tingkat nasional maupun internasional. Salah satu tokoh yang gigih memperjuangkan upaya penyatuan kalender Islam Internasional adalah Mohammad Ilyas. Penelitian ini menunjukkan bahwa konsep pemikiran Mohammad Ilyas tentang Kalender Islam Internasional bertumpu pada hisab imkan ar-rukyah (crescent visibiliy/visibilitas hilal) dan Garis Tanggal Kamariah Antar Bangsa (International Lunar Date Line). Kriteria visibilitas hilal Ilyas menggunakan kombinasi dua parameter, yaitu parameter ketinggian relatif geosentrik (geocentric relative altitude) dan azimut relatif (relative azimut). Kriteria visibilitas hilal yang digunakan oleh Ilyas adalah: (1) Beda tinggi Bulan-Matahari minimum agar hilal dapat teramati adalah $4^{\circ}$ jika beda azimut Bulan-Matahari lebih dari $45^{\circ}$. Jika beda azimutnya $0^{\circ}$, maka beda tinggi Bulan-Matahari harus lebih dari 10.5', (2) Terbenamnya Bulan sekurang-kurangnya 41 menit lebih lambat daripada terbenamnya Matahari dan memerlukan beda waktu yang lebih besar untuk daerah yang lintangnya tinggi, (3) Hilal harus berumur lebih dari 16.5 jam bagi pengamat di daerah tropis dan lebih dari 20 jam bagi pengamat di daerah yang lintangnya lebih tinggi. Aplikabilitas pemikiran Mohammad Ilyas tentang kriteria visibilitas hilal (crescent visibility) sebagai upaya penyatuan kalender Islam Internasional sampai saat ini belum dapat diterima oleh umat Islam di Indonesia. Hal ini disebabkan oleh perbedaan kriteria visibilitas hilal yang dipakai oleh umat Islam di Indonesia (Kementerian Agama RI) dengan kriteria Ilyas. Garis Tanggal Kamariah Antar Bangsa (International Lunar Date Line) yang digagas Ilyas juga selalu berubah-ubah setiap bulan sehingga seringkali menimbulkan perbedaan hari 
dalam memulai bulan baru di suatu daerah atau negara.

Kata Kunci: penyatuan; kalender Islam Internasional; visibilitas hilal.

\section{PENDAHULUAN}

Sebagian besar umat Islam sudah lama mengenal kalender hijriyah, namun kebanyakan kalender yang ada masih bersifat lokal dan regional. Susiknan Azhari menyebutkan bahwa sampai saat ini belum ada satu pun kalender hijriyah yang berlaku secara global. Kalender-kalender yang ada hanyalah kalender lokal atau regional, seperti Kalender Islam Saudi Arabia, India, Inggris, Amerika, Libya, Indonesia, dan Iran. Berdasarkan penelitian atas semua kelender ini terlihat adanya perbedaan antara yang satu dengan lainnya. Kadang-kadang tanggal dalam kalender-kalender tersebut tidak tepat berhubungan dengan visibilitas hilal lokal. ${ }^{1}$

Ada pendapat yang mengatakan bahwa memang terdapat suatu kalender hijriyah yang dapat dianggap bersifat internasional, yaitu kalender hisab urfi. Syamsul Anwar mengemukakan bahwa kalender tersebut merupakan sistem penanggalan tertua dalam sejarah Islam dan digunakan secara luas, bahkan hingga saat ini, akan tetapi kalender ini mempunyai banyak kelemahan, baik secara tehnis maupun kesesuaiannya dengan Sunnah Nabi Muhammad Saw. ${ }^{2}$

Dengan tidak (belum) adanya kalender yang komprehensif dan terunifikasi di kalangan umat Islam menyebabkan seringnya terjadi "kekacauan" pengorganisasian waktu di dunia Islam. Hal ini tampak pada perbedaan hari raya Idul Fitri dan Idul Adha, seperti yang terjadi pada tahun 2007 M (1428 H). Pada tahun tersebut umat Islam

1 Susiknan Azhari, Hisab dan Rukyat (Wacana untuk Membangun Kebersamaan di Tengah Perbedaan), (Yogyakarta: Pustaka Pelajar, 2007), hlm. 25.

2 Syamsul Anwar, "Perkembangan Pemikiran tentang Kalender Islam Internasional", Makalah pada Musyawarah Nasional Ahli Hisab dan Fikih Muhammadiyah, (Yogyakarta: 21-22 Jumadal Saniyah 1429 H/25-26 Juni 2008 M), hlm. 2. berbeda-beda hari dalam melaksanakan Idul Fitri, mulai hari Kamis, Jum'at, Sabtu, bahkan Ahad. ${ }^{3}$

Perbedaan tersebut sangatlah wajar karena penentuan awal bulan hijriyah (kamariyah) didasarkan pada peredaran Bulan mengelilingi Bumi, yakni dengan munculnya hilal (crescent) di ufuk langit barat setelah Matahari terbenam (ghurub asy-Syamsi), di mana untuk menentukan tanggal satu (hilal pertama) umat Islam sampai saat ini belum menemukan kata sepakat, baik yang berprinsip pada metode hisab maupun rukyah. Hal ini berbeda dengan kalender Syamsiyah (Masehi) yang didasarkan pada peredaran (semu) Matahari mengelilingi Bumi, di mana setiap pertama kali terbit, Matahari pasti muncul dari arah Timur ke Barat dengan posisi yang sudah membentuk lingkaran.

Oleh karena peredaran Bulan mengelilingi Bumi dijadikan pedoman dalam penetapan kalender hijriyah, maka peredaran Bulan mengelilingi Bumi menjadi hal yang sangat penting untuk dipelajari dan dipahami oleh umat Islam. Bulan beredar mengelilingi Bumi dalam waktu 27,32166 hari atau 27 hari 7 jam 43 menit 11,42 detik. ${ }^{4}$ Waktu edar ini dikenal dengan nama periode sideris atau syahr nujumi. Selain beredar mengelilingi Bumi, Bulan juga berotasi mengelilingi sumbunya dengan periode yang hampir sama dengan periode siderisnya. Akibatnya bagian Bulan yang menghadap ke Bumi

3 Syamsul Anwar, "Perkembangan ..., hlm. 2.

4 Waktu yang diperlukan oleh Bulan untuk melakukan rotasi dan revolusi adalah sama yaitu 27 hari, 7 jam, dan 43 menit. Syaikh Bakhit menjelaskan bahwa waktu yang ditempuh Bulan dalam mengelilingi orbitnya selama 27 hari 7 jam 43 menit 4 detik. Sedangkan waktu yang diperlukan oleh Bulan dari satu ijtima' ke ijtima' berikutnya adalah 29,5 hari 44 menit 3 detik. Uraian lebih lanjut tentang hal ini, baca Husein Kamaluddin, Ta 'yin Awa'ili asy Syuhur al-' Arabiyyah bi al-Isti'mal al-Hisab,( Jeddah : Dar al-Nasyir, 1979), hlm. 74 . 
akan selalu sama. ${ }^{5}$ Revolusi Bulan ini dijadikan dasar perhitungan bulan kamariyah, tetapi waktu yang dipergunakannya bukan waktu sideris, melainkan waktu sinodis (syahr iqtirani), di mana lama rata-ratanya adalah 29 hari 12 jam 44 menit 2,8 detik. ${ }^{6}$ Dengan adanya peredaran Bulan mengelilingi Bumi (dan juga Bumi mengelilingi Matahari), maka manusia dapat menghitung (hisab) hari-harinya, baik hari-hari yang telah dilalui, sedang atau akan di jalani. Peristiwa tersebut kemudian dijadikan oleh umat manusia untuk membuat penanggalan (kalender), baik kalender syamsiyah maupun kamariah. ${ }^{7}$

Kalender Syamsiyah didasarkan pada peredaran Bumi mengelilingi Matahari, sedangkan kalender kamariyah didasarkan pada peredaran Bulan mengelilingi Bumi. Oleh karena Al-Qur'an dan as-Sunnah tidak menjelaskan tentang kepastian kapan tanggal satu bulan hijriyah, maka penentuan tanggal satu kalender hijriyah kadangkadang berbeda-beda di kalangan umat Islam Islam. Hal ini berakibat pada perbedaan awal-awal bulan penting bagi umat Islam, terutama awal Ramadhan, Syawal, dan Zulhijah. Kasus perbedaan hari raya Idul Fitri pada tahun 1428 H (2007 M) dan tahun-tahun yang lain, telah menyadarkan para ahli di bidang falak (astronomi) untuk terus melakukan kajian dan riset guna mendapatkan kesepakatan dalam penentuan kalender Islam yang bersifat internasional dan terunifikasi. Tokoh-tokoh dalam hal ini di antaranya adalah Mohammad Ilyas, Muhammad Syaukat Audah, Zaki al-Mustafa, dan Jamaluddin Abdur Raziq. ${ }^{8}$ Dalam

5 Susiknan Azhari, Ilmu Falak:Teori dan Praktek, (Yogyakarta : Suara Muhammadiyah, 2004), hlm. 15.

6 Muhyiddin Khazin, Ilmu Falak dalam Teori dan Praktek, (Yogyakarta : Buana Pustaka, 2008), hlm. 132.

7 Kalender Syamsiyah adalah kalender yang didasarkan pada perhitungan Bumi mengelilingi Matahari, sedangkan kalender kamariah adalah kalender yang didasarkan pada perhitungan $\mathrm{Bu}-$ lan mengelilingi Bumi.

8 Moh. Ilyas merupakan ahli astronomi dari Malaysia yang gigih untuk menyatukan kalender Islam tulisan ini penulis akan menekankan pembahasan tentang pemikiran Mohammad Ilyas berkaitan dengan upaya penyatuan kalender Islam Internasional.

Sebelum dikemukakan pengertian tentang kalender Islam, di sini perlu diketahui terlebih dahulu tentang pengertian kalender. Dalam literatur klasik maupun kontemporer istilah kalender biasa disebut dengan tarikh, takwim, almanak, dan penanggalan. ${ }^{9}$ Istilah kalender berasal dari bahasa Inggris modern calendar, dari bahasa Inggris pertengahan, yang asalnya dari bahasa Perancis lama calendier, yang asal mulanya berasal dari bahasa Latin Kalendarium yang artinya buku catatan pemberi pinjaman uang. Dalam bahasa Latin Kalendarium berasal dari kata kalendae atau calendae yang artinya "hari permulaan suatu bulan". ${ }^{10}$

Kalender dalam pengertian istilah terdapat beberapa arti, di antaranya adalah "suatu tabel atau deret halaman-halaman yang memperlihatkan hari, pekan, dan bulan dalam satu tahun tertentu". Pengertian kalender yang lain adalah "Suatu sistem yang dengannya permulaan, panjang, dan

Internasional dengan menawarkan Garis Tanggal Kamariyah Internasional (International Lunar Date Line). Moh. Syaukat Audah (Mohamed Odeh) adalah ahli astronomi Jordania yang telah berhasil membuat software Accurate Times. Ia berupaya menyatukan kalender Islam internasional dengan program melakukan berbagai riset di lembaganya, Islamic Crescent Observatorium Project (ICOP). Jamaluddin Abdur Raziq adalah ahli astronomi Maroko yang menawarkan prinsip "satu hari satu tanggal, satu tanggal satu hari" di seluruh dunia. Di antara tulisan Jamaluddin Abdur Raziq dalam masalah ini adalah at-Taqwim al-Islami, al-Muqarabah asy-Syumuliyyah, dan Bidayah al-Yaum wa Bidayah al-lail wa an- $\mathrm{Na}$ har dalam < www.amastro.ma/articles/art-debjour.pdf $>$, sedangkan Zaki al-Mustafa adalah ahli astronomi Saudi Arabia yang gigih menyatukan kalender Islam internasional melalui inovasi-inovasi Kalender Ummul Qura.

9 Susiknan Azhari, Ilmu Falak (Perjumpaan Khazanah Islam dan Sains Modern), (Yogyakarta: Suara Muhammadiyah, Cetakan Kedua, 2007), hlm. 82.

10 Ruswa Darsono, Penanggalan Islam (Tinjauan Sistem, Fiqh, dan Hisab), (Yogyakarta: Labda Press, 2010), hlm. 27. 
pemecahan bagian tahun ditetapkan, misalnya Kalender Julian, Kalender Gregorius, Kalender Hijriyah, dan lain-lain". Dalam literatur yang lain kalender adalah "Sebuah sistem pengorganisasian satuan-satuan waktu untuk tujuan menghitung waktu melewati jangka yang panjang. Menurut konvensi, hari adalah satuan kalender terkecil dari waktu. Pengukuran bagian-bagian waktu dalam sehari dinamakan tata-waktu". ${ }^{11}$

Adapun pengertian Kalender Islam atau Kalender Hijriyah adalah kalender yang terdiri atas dua belas bulan kamariah, di mana setiap bulan berlangsung sejak penampakan pertama Bulan sabit (hilal/crescent) hingga penampakan berikutnya (29 hari atau 30 hari). Sementara itu dalam istilah lain dikemukakan bahwa Kalender Hijriyah atau Tarikh Hijriyah adalah penanggalan Islam yang dimulai dengan peristiwa hijrahnya Rasulullah Saw. ${ }^{12}$

Moedji Raharto sebagaimana dikutip oleh Susiknan Azhari mengemukakan bahwa sistem Kalender Hijriyah atau Penanggalan Islam adalah sebuah sistem kalender yang tidak memerlukan pemikiran koreksi karena betul-betul mengandalkan fenomena fase Bulan. ${ }^{13}$ Thomas Djamaluddin menjelaskan bahwa kalender kamariah merupakan kalender yang paling sederhana karena mudah dibaca di alam. Awal bulan dalam kalender hijriyah ditandai oleh penampakan hilal (visibilitas hilal) sesudah Matahari terbenam (magrib). ${ }^{14}$

Sementara itu Mohammad Ilyas menjelaskan bahwa Kalender Islam adalah kalender yang didasarkan atas perhitungan kemungkinan hilal atau Bulan sabit terlihat pertama kali dari sebuah tempat pada suatu negara. ${ }^{15}$ Dengan ungkapan lain bahwa

11 Ruswa Darsono, Penanggalan ..., hlm. 27.

12 Susiknan Azhari, Ilmu Falak ..., hlm. 83.

13 Susiknan Azhari, Ilmu Falak ..., hlm. 83.

14 Lihat T. Djamaluddin, "Kalender Hijriyah: Tuntutan Penyeragaman Mengubur Kesederhanaannya", dimuat dalam harian Republika, Jum'at, 10 Juni 1994, hlm.8.

15 Mohammad Ilyas, A Modern Guide to Astronomical Calculation of Islamic Calendar, Times, and Qibla, (Kuala Lumpur: Berita Publishing, yang menjadi dasar dalam penentuan kalender Islam adalah visibilitas hilal (crescent visibility) di suatu negara.

Dari uraian di atas dapat diperoleh penjelasan bahwa pada mulanya yang menjadi patokan kalender Islam adalah hijrahnya Nabi Muhammad Saw. dari Mekah ke Madinah dan penampakan hilal, bukannya hisab atau rukyat, namun demikian apabila penampakan hilal menjadi standar dan diaplikasikan di setiap wilayah maka akan menemukan kesulitan karena fenomena alam yang tidak mendukung. ${ }^{16}$

\section{METODE PENELITIAN}

Jenis penelitian ini adalah library research, dengan menggali semua data-data yang berupa dokumen yang tertulis, baik dalam buku-buku karya ilmiah atau tulisan yang berkaitan pemikiran Mohammad Ilyas tentang penyatuan kalender Islam International. Sedangkan pendekatannya menggunakan pendekatan filosofis, yaitu pendekatan untuk meneliti pemikiran tokoh dan mengungkapkan dibalik hakekat segala sesuatu yang nampak dari berbagai teks tulisan dan catatan naskah-naskah yang telah diterbitkan. Islam dengan ke universalannya dalam ajarannya, serat mengandung hikmah bagi segenap manusia. Sedangkan mengungkap hikmah ajaran Islam itu merupakan kerja filsafat, dan inilah yang disebut aspek esoteris agama. ${ }^{17}$

Karena penelitian ini berupa teks tertulis, maka paradigma yang digunakan adalah berdasarkan penelitian kualitatif. ${ }^{18}$ Penelitian kualitatif dalam penulisan ini menitikberatkan pada proses dengan metode analisis deduktif. ${ }^{19}$ Oleh karena itu,

1984), hlm. 58-59.

16 Susiknan Azhari, Ilmu Falak ..., hlm. 84.

17 Ibid, hlm. 15

18 Penelitian kualitatif adalah penelitian yang menitikberatkan pada proses dengan metode analisis deduktif, induktif, komparatif, interpretative, analisis isi, hermeneutic dan verstehen. Lihat, Sudarno Shobron, dkk, Pedoman Penulisan Tesis, (Surakarta, Sekolah Pascasarjana UMS, 2014), hlm. 11

19 Sudarno Shobron, dkk, Pedoman Penulisan Te- 
penelitian kualitatif merupakan prosedur yang menghasilkan data deskriptif berupa teks tertulis dari orang yang perilaku atau pemikiran yang dapat diamati. Pendekatan ini juga diarahkan pada latar belakang dan individu tersebut secara utuh (holistik). Orang dan perilaku ini bisa juga berupa teks yang tertulis. Sedangkan langkah-langkah yang digunakan adalah sebagai berikut: 1) Paradigma penelitian, 2) Jenis Penelitian, 3) Pendekatan, 4) Sumber Data, 5) Pengumpulan Data, 6) Validitas Data, 7) Analisis Data.

Sumber data terdiri dari dua bagian yaitu sumber data primer dan sekunder. Perta$m a$, sumber primer akan menelaah berbagai karya tulis Mohammad Ilyas, baik berupa buku-buku maupun artikel-artikelnya. Kedua, sumber sekunder yaitu data-data yang bersumber pada buku-buku serta tulisan-tulisan, atau karangan orang lain yang dapat diperoleh dari: buku, jurnal, majalah, hasil-hasil penelitian (tesis dan disertasi), dan sumber-sumber lainnya yang sesuai (internet, koran dll), yang berhubungan dengan penelitian tersebut.

Teknik analsis datanya menggunakan Content analysis, sebagaimana ungkapan Suryabrata ${ }^{20}$ bahwa conten analysis adalah menganalisis data sesuai dengan kandungan isinya. Dengan ini data-data yang penulis kumpulkankan adalah bersifat deskriptif dan data tekstual yang bersifat fenomenal, maka dalam mengelola data-data tersebut penulis menggunakan analisis ini. Dengan analisis ini penulis melakukan analisis data secara ilmiah dan menyeluruh tentang konsepsi dan pemikiran Mohammad Ilyas tentang penyatuan kalender Islam Internasional.

\section{HASIL DAN PEMBAHASAN}

Kalender adalah sebuah sistem perhitungan yang bertujuan untuk pengorganisasian waktu dalam periode tertentu. Bulan merupakan sebuah unit yang merupakan bagian dari kalender. Hari merupakan unit

sis..., hlm. 11

20 Sumardi Suryabrata, Metode Penelitian, Jakarta: Rajawali Press, 1998, hlm. 94. kalender (almanak) terkecil, dan sistem waktu yaitu jam, menit, dan detik. ${ }^{21}$

Macam-macam kalender cukup banyak, bahkan dalam perhitungan mempunyai aturan siklus sendiri. Di samping itu ada kalender yang mempunyai ciri-ciri tersendiri. Setidaknya terdapat tiga macam kalender berdasarkan daur astronomis, yaitu:

\section{Kalender Sistem Matahari (Solar System)}

Kalender Matahari menggunakan pergerakan Matahari sebagai dasar perhitungan, di mana patokan utamanya adalah ketika Matahari berkedudukan di equator atau ketika lama siang dan malam hari sama panjangnya pada awal musim semi di bagian Bumi belahan utara. ${ }^{22}$

Pada prinsipnya sistem ini adalah sistem penanggalan yang menggunakan perjalanan Bumi ketika mengorbit Matahari. Ada dua pertimbangan yang dipergunakan dalam kalender ini, yaitu pertama, adanya pergantian siang dan malam. Kedua, adanya pergantian musim yang diakibatkan oleh orbit Bumi yang berbentuk ellips ketika ia mengelilingi Matahari. Adapun waktu yang digunakan oleh Bumi dalam mengelilingi Matahari adalah 365 hari, 5 jam, 48 menit, 46 detik. ${ }^{23}$ Kelebihan kalender ini adalah kesesuaiannya dengan musim karena dasar perhitungan pada awalnya berasal dari pergeseran musim. Contoh kalender ini adalah Kalender Gregorian (Kalender Syamsiyah) yang kita gunakan sehari-hari saat ini. Beberapa model lain kalender yang menggunakan sistem solar di antaranya adalah: Kalender Mesir Kuno, Kalender Romawi Kuno, Kalender Julian, Kalender Gregorian

\section{Kalender Sistem Bulan (Lunar System)}

Kalender ini menggunakan sistem Bulan, artinya perjalanan Bulan ketika mengorbit Bumi (Bulan berrevolusi terhadap Bumi). Kalender ini murni menggunakan

21 Slamet Hambali, Almanak Sepanjang Masa, (Semarang: Program Pascasarjana IAIN Walisongo, 2011), hlm. 3.

22 Ruswa Darsono, Penanggalan ..., hlm. 32.

23 Slamet Hambali, Almanak ...,hlm. 3-4. 
lunar disebabkan mengikuti fase Bulan. Kalender sistem lunar, pada sisi lain tidak terpengaruh terhadap perubahan musim, sebab kemunculan Bulan dalam satu tahun selama dua belas kali amat mudah diamati. ${ }^{24}$

Kalender Bulan memanfaatkan perubahan fase Bulan sebagai dasar perhitungan waktu. Bulan dalam perjalanannya mengelilingi Bumi akan mengalami perubahan fase-fase. Fase Bulan akan berubah dari bulan mati, Bulan sabit, Bulan seperempat, Bulan separoh, Bulan purnama, Bulan separoh, Bulan sabit, dan kembali ke mati lagi.

Berkaitan dengan hilal di sini perlu diperhatikan fase-fase Bulan ketika Bulan melakukan perjalanan mengelilingi Bumi. David Morrison menyebutkan ada empat fase penting bagi Bulan ${ }^{25}$, yaitu (1) Bulan baru (new moon), (2) kuartal pertama (first quarter), (3) Bulan purnama (full moon), dan (4) kuartal ketiga atau terakhir (third quarter or last quarter). ${ }^{26}$ Di antara keempat fase ini, dalam kaitannya dengan awal bulan kamariah, yang perlu dicermati adalah pada saat Bulan baru (new moon) karena pada fase inilah Bulan sabit (hilal) terjadi. Fase pertama ini ditandai dengan suatu posisi di mana saat gerakan Bulan mengelilingi Bumi secara bersamaan, terdapat bagian Bulan yang terkena sinar Matahari semula sangat kecil berbentuk sabit (crescent). Bagian ini semakin hari semakin besar. Saat Bulan sabit pertama kali dapat dilihat inilah

24 Slamet Hambali, Almanak ..., hlm. 13.

25 David Morrison dan Tobias Owen, The Planetary System, (New York: Addison-Wesley Publishing, 1940), hlm. 6-7.

26 Fase pertama ditandai dengan bagian Bulan yang terkena sinar Matahari semula sangat kecil yang membentuk hilal. Tono Saksono menjelaskan bahwa kuartal pertama (first quarter) ditandai dengan Bulan yang semakin membesar, bahkan sudah kelihatan separoh, yakni terjadi sekitar seminggu sejak awal Bulan. Full moon (Bulan purnama) terjadi sekitar dua minggu dari hilal, di mana Bulan telah mengelilingi Bumi separoh perjalanan, dan kuartal terakhir (last quarter) terjadi sekitar tiga minggu setelah hilal, di mana Bulan terbit lebih awal sekitar 6 jam daripada Matahari. Lihat Tono Saksono, Mengkompromikan ..., hlm. 33-38. yang dinamakan hilal. ${ }^{27}$

Kalender lunar ini lamanya rata-rata adalah 29 hari 12 jam 44 menit 3 detik (29.5306 hari). Periode ini disebut dengan satu bulan yang dikenal dengan periode sinodis. Panjang tahun dalam kalender lunar adalah 12 bulan (12 x 29.5306 hari), yakni 354 hari 8 jam 48 menit 34 detik (354.3762 hari). Kalender ini biasa digunakan untuk keperluan ibadah. Kalender Bulan yang tertua diketahui berusia 17.000 tahun. Bukti keberadaan kalender ini terpahat di dinding Gua Lascaux, Perancis. ${ }^{28}$ Beberapa kalender yang menggunakan sistem lunar ini di antaranya adalah Kalender Hijriyah (Islam/ Arab) dan Kalender Jawa Islam.

\section{Kalender Sistem Bulan-Matahari (Luni-} Solar System)

Kalender ini menggunakan Bulan Matahari, artinya perjalanan sistem Bulan dan Matahari di kalender pertama memang berdasarkan atas peredaran Bulan, namun hal ini tidak akurat dengan peredaran Bumi dalam mengelilingi Matahari, kemudian menjadi dasar untuk waktu penanggalan (solar) karena sistem peredaran Bulan (lunar) tidak cocok dengan Bumi mengelilingi Matahari. ${ }^{29}$

Dalam kalender Matahari awal bulan tidak harus menyesuaikan dengan bentuk fase Bulan. Tidak demikian halnya dengan kalender Bulan-Matahari (Luni-Solar System). Lama kalender ini adalah 365.2422 hari, namun pergantian bulan disesuaikan dengan periode fase Bulan ( 1 bulan $=29.5306$ hari). Normalnya kalender ini terdiri atas 12 (dua belas) bulan. Satu bulan kadang berjumlah 29 hari, dan kadang 30 hari. Apabila dihitung, dalam satu tahun berjumlah 354 hari (12 x 29.5306 hari), lebih cepat 11 hari dari yang seharusnya.Agar kalender ini tetap konsisten dengan pergerakan Matahari, maka dibuatlah tahun kabisat yang terdiri atas 13 bulan sebanyak 7 kali dalam 19 tahun. Kelebihan kalender ini adalah konsistensinya dengan musim sekaligus penggu-

27 Tono Saksono, Mengkompromikan ..., hlm. 33.

28 Ruswa Darsono, Penanggalan ..., hlm. 32-33.

29 Slamet Hambali, Almanak ..., hlm. 18. 
naannya untuk keperluan ibadah. ${ }^{30}$ Contoh kalender Matahari- Bulan adalah kalender Cina (Imlek), kalender Arab pra-Islam, dan kalender Yahudi.

Pada awalnya, baik kalender sistem kalender Bulan (lunar) maupun kalender Matahari (solar) merupakan gabungan, namun belakangan sistem kalender lunar dan solar menjadi berdiri sendiri. Pada perayaan-perayaan agama, kalender sistem lunar pada umumnya dijadikan sebagai petunjuk, seperti pada peringatan Cristian Easter. Diawali pada agama Hindu dan Yom Kippur pada agama Yahudi, demikian juga dengan hari-hari raya Islam. Jadi pada perayaan agama-agama kalender yang digunakan lebih banyak sistem kalender Bulan (lunar), sedangkan untuk kepentingan bisnis dan catatan administrasi lebih banyak menggunakan sistem kalender Matahari (solar). ${ }^{31}$

Pada saat ini kita mempunyai dua sistem yang berjalan berdampingan. Di satu sisi, kalender Bulan mempunyai latar belakang universal, yang pada sistem solar (Matahari) dibatasi dengan batas-batas geografis. Sistem penanggalan dengan peredaran Bulan memang tidak berhubungan sepenuhnya dengan masalah pertanian yang menyangkut cuaca dan panen, sedangkan musim lebih banyak berhubungan dengan sistem peredaran Matahari, seperti juga masa panen pertanian. ${ }^{32}$ Beberapa kalender yang didasari dengan sistem ini di antaranya adalah Kalender Babilonia, Kalender Yahudi, dan Kalender China.

\section{Pemikiran Mohammad Ilyas}

Salah satu tokoh yang gigih memperjuangkan upaya penyatuan kalender Islam Internasional adalah Mohammad Ilyas, seorang ahli atmosfir dan astronomi dari Malaysia. Ilyas mengemukakan bahwa dalam rangka mewujudkan penyatuan kalender Islam Internasional, maka kajian ilmiah harus dilakukan dengan data-data empiris yang diperoleh dari fenomena alam atas dasar kajian astronomi. Berkaitan dengan

30 Ruswa Darsono, Penanggalan ..., hlm. 33.

31 Slamet Hambali, Almanak ..., hlm. 18-19.

32 Slamet Hambali, Almanak ..., hlm. 19. masalah ini, Mohammad Ilyas mempunyai dua gagasan, yakni: (1) Hisab imkan ar-rukyah (crescent visibility), yang sekaligus untuk menemukan Garis Tanggal Kamariah Antar Bangsa (International Lunar Date Line). Hisab ini harus dilakukan di berbagai tempat di belahan dunia untuk menemukan titik-titik imkan ar-rukyah (kemungkinan hilal dapat dilihat), (2) Garis Tangal Kamariah Antar Bangsa (International Lunar Date Line/ILDL). ${ }^{33}$ Garis tersebut dihubungkan antar wilayah guna mendapatkan keseragaman hilal. Berkaitan dengan hal ini, Ilyas membagi Bumi menjadi tiga zona kalender, yaitu Benua Amerika, Eropa, dan Asia Pasifik. Pokokpokok pemikiran Mohammad Ilyas tersebut adalah sebagai berikut:

\section{Kriteria Visibilitas Hilal (Crescent Vis- ibility)}

Di kalangan umat Islam terdapat dua macam metode untuk menentukan masuknya bulan baru, yaitu pertama, metode rukyah yakni melihat hilal secara langsung pada hari ke-29 (malam ke-30) bulan berjalan. Apabila sore itu hilal (crescsent) dapat dilihat, maka malam itu dan keesokan harinya dinyatakan sebagai bulan baru, dan apabila sore itu hilal tidak terlihat, maka malam itu dan keesokan harinya merupakan hari ke-30 dari bulan yang sedang berjalan. Kedua, metode hisab, yakni perhitungan dengan kriteria astronomis tertentu untuk memasuki bulan baru. Apabila kriteria tersebut telah terpenuhi, maka malam itu dan keesokan harinya dinyatakan sebagai bulan baru, dan apabila kriteria itu belum terpenuhi, maka malam itu dan keesokan harinya merupakan hari ke-30 dari bulan yang sedang berjalan. ${ }^{34}$

Pada masa Nabi Muhammad saw. metode yang digunakan untuk menentukan awal bulan baru adalah dengan melihat

33 Mohammad Ilyas, A Modern Guide to Astronomical Calculation of Islamic Calendar, Times, and Qibla, (Kuala Lumpur: Berita Publishing, 1984), hlm. 115-120.

34 Syamsul Anwar, Interkoneksi Studi Hadis dan Astronomi, (Yogyakarta: Suara Muhammadiyah, 2011), hlm. 56-57. 
hilal (rukyah). Hal ini disebabkan ilmu falak belum berkembang pada masa Nabi. Oleh karena itu untuk dapat membuat perkiraan kapan Nabi saw. dapat merukyat hilal maka dibuatlah kriteria-kriteria tertentu. Upaya untuk melihat hilal dengan kriteria visibilitas hilal (crescent visibility) sudah sangat tua dalam sejarah peradaban manusia, setidaknya dapat dicatat sejak zaman Babilonia. Orang-orang Babilonia merumuskan dua kriteria untuk dapat melihat hilal, yaitu (1) usia hilal di tempat terbenamnya Matahari lebih dari 24 (dua puluh empat) jam, dan (2) Mukus hilal lebih dari 48 (empat puluh delapan) menit. ${ }^{35}$

Meskipun kriteria Babilonia ini sederhana, namun bertahan cukup lama dan tidak banyak mengalami perubahan hingga beberapa waktu belum lama ini. Pada zaman Islam kriteria ini juga tetap populer sebagaimana tampak dalam pernyataan Al-Battani (w. $317 \mathrm{H}$ ) tentang orang zaman kuno: "Mereka menegaskan bahwa tidak mungkin melihat hilal apabila usianya kurang dari sehari semalam. Apabila dipelajari lebih lanjut, akan ternyata bahwa pernyataan ini merupakan dasar dari praktik yang dijalankan" ${ }^{36}$

Namun demikian para ahli astronomi Muslim juga mengembangkan daftar-daftar untuk menentukan visibilitas hilal. Hal yang lebih penting lagi mereka juga telah menyadari arti penting parameter lebar hilal (crescent's width) untuk menentukan visibilitasnya. ${ }^{37}$

Pada zaman modern kecenderungan kepada hisab semakin menguat. Hal ini disebabkan adanya tuntutan untuk dapat menyatukan kalender Islam yang mustahil dilakukan berdasarkan metode rukyat. Temu Pakar II untuk "Pengkajian Perumusan Kalender Islam" yang diselenggarakan oleh Islamic Educational, Scientific and Cultural Organization (ISESCO) bekerja sama dengan Asosiasi Astronomi Maroko dan Jam'iyyat ad-Da'wah al-Islamiyyah al-'Alami-

35 Mohammad Ilyas, A Modern ..., hlm. 84. Lihat juga Syamsul Anwar, Interkoneksi ..., hlm. 57.

36 Syamsul Anwar, Interkoneksi ..., hlm. 58.

37 Mohammad Ilyas, A Modern ..., hlm. 57. yyah di Rabat, Maroko pada tanggal 15-16 Oktober 2008 memutuskan penggunaan hisab dalam upaya penyatuan kalender Islam Internasional. Salah satu keputusannya adalah sebagai berikut:

"Masalah Penggunaan Hisab: Para peserta menyepakati bahwa pemecahan problematika penetapan bulan kamariah di kalangan umat Islam tidak mungkin dilakukan kecuali berdasarkan penerimaan terhadap hisab dalam menetapkan awal bulan kamariah, seperti halnya penggunaan hisab untuk menentukan waktu-waktu shalat, dan menyepakati pula bahwa penggunaan hisab itu adalah untuk penolakan rukyat dan sekaligus penetapannya". ${ }^{38}$

Di kalangan umat Islam perbedaan pemahaman terhadap dalil-dalil tentang hisab dan rukyah masih banyak terjadi, misalnya perbedaan pemahaman terhadap kata "syahida" dalam Surat Al-Baqarah/2: 185. Para ulama berbeda pendapat dalam menafsirkan kata tersebut. Mustafa al-Maragi dan Wahbah az-Zuhaili menafsirkan kata "syahida" dengan rukyah dan "asy-syahra" sebagai hilal, sehingga syuhud asy-syuhur dipahami sebagai rukyat al-hilal. ${ }^{39}$

Ibn Kasir, salah seorang ahli tafsir $b i$ al-ma'sur, menafsirkan kata "faman syahida minkum asy-syahra" dengan "orang yang berada (muqiman) di suatu negeri ketika bulan Ramadan tiba"..$^{40}$ Rasyid Rida menafsirkan kata "syahida" dalam ayat tersebut dengan "hadara" (hadir), yakni barang siapa yang hadir (di suatu negeri) pada saat masuknya bulan Ramadan dan ia tidak bepergian, maka hendaklah ia berpuasa. ${ }^{41}$ Sementara

38 Rasyid Rida dkk., Hisab Bulan Kamariah: Tinjauan Syar'i tentang Penetapan Awal Ramadan, Syawal, dan Zulhijah, alih bahasa Syamsul Anwar, (Yogyakarta: Suara Muhammadiyah, 2008), hlm. 81.

39 Lihat Ahmad Mustafa al-Maragi, Tafsir al-Maragi, (Beirut: Dar al-Fikr, t.t., Juz II), hlm. 172. Wahbah az-Zuhaili, At-Tafsir al-Munir fi al'Aqidah wa asy-Syari'ah wa al-Manhaj, (Beirut: Dar al-Fikr, t.t., Juz II), hlm. 142.

40 Abi al-Fida' Isma'il Ibn Kasir, Tafsir al-Qur'an al- 'Azim, (Jakarta: Dar al-Ihya', t.t., Juz I), hlm. 216.

41 Muhammad Rasyid Rida, Tafsir al-Manar, (Beirut: Dar al-Kutub al-'Ilmiyyah, 2005), Jilid II, 
itu Quraish Shihab memahami kata tersebut dengan "hadir" pada bulan itu, yakni bagi orang yang berada di negeri tempat tinggalnya atau mengetahui munculnya awal bulan Ramadan. ${ }^{42}$

Hisab imkan ar-rukyah Mohammad Ilyas merupakan kriteria yang menggunakan kombinasi dua parameter, yaitu parameter ketinggian relatif geosentrik (geocentric relative altitude) dan parameter azimut relatif (relative azimut). Berkaitan dengan hal ini hanya terdapat satu kategori imkan ar-rukyah, yaitu rukyah dengan mata telanjang saja. ${ }^{43}$ Lebih jelasnya kriteria visibilitas hilal (crescent visibility) yang dikemukakan oleh Ilyas adalah sebagai berikut: (1) Beda tinggi Bulan-Matahari minimum agar hilal dapat teramati adalah $4^{\circ}$ apabila beda azimut Bulan-Matahari lebih dari $45^{\circ}$. Apabila beda azimutnya $0^{\circ}$, maka beda tinggi Bulan-Matahari harus lebih dari $10.5^{\circ}$, (2) Terbenamnya Bulan sekurang-kurangnya 41 menit lebih lambat daripada terbenamnya Matahari dan memerlukan beda waktu yang lebih besar untuk daerah yang lintangnya tinggi, (3) Hilal harus berumur lebih dari 16.5 jam bagi pengamat di daerah tropis dan lebih dari 20 jam bagi pengamat di daerah yang lintangnya lebih tinggi. ${ }^{44}$

\section{Garis Batas Tanggal Hijriyah Interna- sional (International Lunar Date Line)}

Pemikiran Ilyas yang lain dalam rangka penyatuan kalender Islam Internasional adalah Garis Batas Tanggal Hijriyah Antar Bangsa atau yang populer dengan istilah International Lunar Date Line (ILDL). Gagasan

hlm. 131.

42 M. Quraish Shihab, Tafsir al-Misbah, (Jakarta: Lentera Hati, Juz I), hlm. 404. Quraish Shihab, meskipun menafsirkan kata syahida dalam surat al-Baqarah ayat 185 itu dengan "hadir" nya seseorang pada saat tibanya bulan Ramadan, baik dengan cara melihat atau melakukan perhitungan, namun demikian ia dalam penjelasan berikutnya lebih cenderung untuk menyarankan umat Islam agar mengikuti penentuan awal bulan kamariah dengan rukyah yang dilaksanakan di Mekah.

43 Mohammad Ilyas, Astronomy ..., hlm. 15-16.

44 Mohammad Ilyas, Astronomy ..., hlm. 97-98, dan 153. ini merupakan gagasan orisinil Ilyas yang banyak direspons oleh banyak ilmuwan dengan berbagai komentar.

Garis Batas Tanggal adalah garis yang menghubungkan daerah-daerah di permukaan Bumi di mana Matahari dan Bulan terbenam secara bersamaan. Garis Batas Tanggal biasanya digunakan oleh kelompok yang berpegang pada ufuk mar' $i{ }^{45}$ Garis Batas Tanggal tidak bisa dijadikan pedoman langsung dalam menentukan posisi hilal untuk suatu tempat. Hal ini disebabkan oleh beberapa faktor, yaitu: (a) Data terbenam Matahari yang dijadikan pedoman dalam melukis garis itu diambil rata-rata dari tiga hari, dan (b) Data terbenam Matahari dan terbenam Bulan tidak memperhatikan kerendahan ufuk. ${ }^{46}$

Garis Batas Tanggal Kamariah antar Bangsa yang digagas oleh Ilyas ini dilakukan dengan cara melakukan hisab imkan ar-rukyah di berbagai tempat secara global untuk menemukan titik-titik imkan ar-rukyah, misalnya hisab dimulai dari titik $0^{\circ}$ guna menemukan titik-titik visibilitas hilal (crescent visibility) pertama, kemudian dilakukan pada garis lintang berikutnya ke utara dan ke selatan dengan interval $5^{\circ}$ sampai $15^{\circ}$ guna menemukan titik imkan ar-rukyah. Apabila hal tersebut telah dilakukan dan telah ditemukan titik-titik imkan ar-rukyah, maka titik-titik imkan ar-rukyah tersebut dihubungkan dengan satu garis sehingga akan ditemukan garis lengkung (parabolik) yang lengkungannya menjorok ke timur. Namun demikian Ilyas juga menerima kemungkinan garis imkan ar-rukyah melengkung itu dibuat tegak lurus demi suatu kepraktisan. ${ }^{47}$

Garis lengkung tersebut akan memisahkan Bumi menjadi dua kawasan, yaitu kawasan sebelah barat dan sebelah timur. Kawasan sebelah barat adalah kawasan yang mungkin melihat hilal dan kawasan sebelah timur merupakan kawasan yang

45 Susiknan Azhari, Ensiklopedi Hisab Rukyat, (Yogyakarta: Pustaka Pelajar, Cetakan kedua, 2008), hlm. 69.

46 Susiknan Azhari, Ensiklopedi ..., hlm. 69.

47 Syamsul Anwar, Interkoneksi ..., hlm. 108. 
tidak mungkin dapat melihat hilal (dengan catatan bahwa garis tersebut muncul berpindah-pindah setiap bulan dan tidak bersifat eksak). Apabila garis ini membelah suatu negara menjadi dua, maka dapat ditarik ke arah timur sesuai dengan batas negara yang bersangkutan. Garis inilah yang disebut Ilyas dengan International $\mathrm{Lu}$ nar Date Line (ILDL) atau Garis Tanggal Kamariah Antar Bangsa. Atas dasar ILDL ini, Ilyas merumuskan Kalender Islam Internasional, namun bersifat zonal dan membagi Bumi menjadi tiga zona tanggal, yaitu zona Asia-Pasifik, zona Eropa-Asia Barat-Afrika, dan zona Amerika. ${ }^{48}$

Ilyas melihat bahwa dengan Garis Tanggal Kamariah Antar Bangsa (International Lunar Date Line) diharapkan semangat persatuan umat Islam di seluruh dunia dapat dibina. Bagi Ilyas, Garis Tanggal Kamariah antar bangsa digunakan karena paling mudah menghitungnya dan dapat dipakai sebagai pemandu awal oleh pengguna rukyah yang dipandu hisab sebelum menghitung data rukyah lokal. Garis Tanggal Kamariah Antar bangsa tersebut membagi Bumi dalam dua bagian yang pada saat magrib Bulan masih di atas ufuk atau telah tenggelam. Pembagian ini menjadikan pemikiran Ilyas mewariskan problem klasik, yaitu persoalan matlak. ${ }^{49}$

Keberlakuan rukyah hilal atau matlak ini berangkat dari pemikiran bahwa Bumi berbentuk bulat, bukan seperti selembar kertas. Efek dari bentuk Bumi tersebut adalah ada daerah yang dapat melihat hilal lebih awal dari yang lain. Tidak ada batasan fisik kuantitatif yang dapat dibuat dengan menentukan matlak tanpa mempertimbangkan kondisi sebaran penduduk dan geopolitik pada suatu masa. Gagasan rukyah global akan banyak berbenturan dengan sekian banyak kesulitan, termasuk memaksa orang untuk berjaga menunggu kesaksian hilal yang belum pasti atau mengqada' puasa apabila telah lewat. Sementara itu membuat batasan radius sekian derajat juga

48 Syamsul Anwar, "Perkembangan ..., hlm. 8-9. 49 Susiknan Azhari, Hisab dan Rukyat ...,hlm. 31. tidak ada alasan ilmiah yang sahih. ${ }^{50}$

Konsep Garis Tanggal Kamariah Antar Bangsa (International Lunar Date Line) yang digagas oleh Mohammad Ilyas memang sangat prospektif dalam rangka membangun Kalender Islam Internasional, namun konsep ini sebagaimana dikemukakan oleh Thomas Djamaluddin tidak akan bernilai guna apabila pola pikir masyarakat Muslim masih terbelenggu dengan konsep Garis Tanggal Internasional (International Date Line) yang ada dalam kalender syamsiyah. Dengan kata lain umat Islam akan hidup dalam dua garis tanggal. ${ }^{51}$

Definisi hari berdasarkan Garis Tanggal Internasional (International Date Line) yang disepakati melintasi garis bujur $180^{\circ}$ di Samudra Pasifik, sementara itu definisi awal bulan kamariah berdasarkan garis tanggal kamariah yang tidak tetap posisinya, tergantung posisi Bulan dan Matahari. ${ }^{52}$

Gagasan yang dikemukakan Ilyas tentang ILDL ini bukannya hendak menegasikan realitas empiris, melainkan berancang menunjukkan inti masalah jika diinginkan kajian ilmiah atas kalender Islam Internasional, yaitu bahwa kajian semacam itu tidak akan pernah terwujud kecuali melalui pendekatan eksakta dan humaniora dari sistem budaya dan realitas yang melingkupinya. ${ }^{53}$

Garis Tanggal Kamariah antar Bangsa dalam kalender hijriyah ini berbeda dengan Garis tanggal dalam kalender Syamsiyah yang dikenal dengan istilah International Date Line (IDL). Para ahli geografi mendefinisikan bahwa International Date Line (Garis Batas Tanggal Internasional) dalam kalender syamsiyah adalah garis-garis meridian (bujur) sebagai garis-garis maya melalui kutub Utara dan Selatan mengelilingi Bumi.

50 T. Djamaluddin, "Redefinisi Hilal Menuju Titik Temu Kalender Hijriyah”, Makalah pada Seminar Kelas Program Doktor Ilmu Falak IAIN Walisongo Semarang, September 2010, hlm. 3.

51 T. Djamaluddin, "Kalender Hijriyah: Tuntutan Penyeragaman Mengubur Kesederhanaannya", dalam harian Republika, Jum'at, 10 Juni 1994, hlm. 8 .

52 Susiknan Azhari, Hisab dan Rukyat ..hlm. 31-32.

53 Susiknan Azhari, Hisab ...hlm. 29. 
Garis-garis tersebut diberi sebutan sesuai dengan titik lintasannya (Timur atau Selatan) dengan mengacu garis meridian Greenwich Observatory di London sebagai garis meridian $0^{\circ}$. Tahun 1884 pada International Meridian Conference, di Washington yang dihadiri perwakilan dari 25 negara, Garis Meridian Greenwich dipakai secara International sebagai meridian utama yang merupakan basis perhitungan waktu Greenwich Mean Time (GMT). Berjarak $180^{\circ}$ dari garis tersebut didefinisikan sebagai garis tanggal international (International Date Lines). ${ }^{54}$ Dengan kata lain Garis Tanggal Internasional (International Date Line) adalah garis maya pada permukaan Bumi yang mendekati garis bujur $180^{\circ}$ sebagai pemisah tanggal dalam kalender gregorian/Masehi. ${ }^{55}$

Umat Islam dalam menentukan hari (Senin, Selasa, ...dan seterusnya) selalu mengikuti garis tanggal Internasional tersebut di atas, namun dalam penentuan tanggal kalender Islam mengikuti garis tanggal secara dinamis yang setiap bulannya berubah-ubah. Hal ini disebabkan garis tanggal dalam kalender hijriyah tidak selalu tetap seperti pada garis tanggal dalam kalender syamsiyah. Kondisi ini disebabkan belum adanya kesepakatan di antara umat Islam tentang garis tanggal kamariah tersebut.

Ada beberapa kesulitan dengan konsep garis tanggal kamariah Internasional (International Lunar Date Line) yang berpindah-pindah setiap bulan. Garis tanggal dalam konsep ini hanya digunakan untuk mendefinisikan awal bulan kamariah, kapan dan di mana ia dimulai. Pendefinisian ini tidak diselaraskan dengan pendefinisian hari dari mana ia dimulai, sehingga tidak ada sinkronisasi antara pendefinisian awal bulan dengan pendefinisian hari. ${ }^{56}$

Berkaitan dengan masalah ini definisi hari yang dimaksud adalah "hari syar'i",

54 Khafid, "Garis Tanggal Internasional: Antara Penanggalan Miladiyah dan Hijriyah", makalah disampaikan dalam Musyawarah Nasional Penyatuan Kalender Hijriyah pada tanggal 17-19 Desember 2005 di Jakarta, hlm. 4.

55 Khafid, "Garis Tanggal ..., hlm. 4.

56 Syamsul Anwar, Interkoneksi ..., hlm. 109. yakni hari yang dimulai pada saat Matahari terbenam. Dari sini timbul kesulitan, dan bahkan inkonsistensi kalender. Ketika garis tanggal pada awal bulan baru bergerak ke barat apakah batas dari mana hari (syar'i) dimulai juga ikut bergerak dari garis tanggal bulan baru ke garis tanggal bulan baru berikutnya.

Gagasan-gagasan pembuatan garis tanggal kamariah Internasional (International Lunar Date Line) yang dipelopori oleh Mohammad Ilyas sejak tahun 1978 sampai saat ini belum dapat diaplikasikan. Ilyas mengemukakan bahwa di antara penyebab belum diterimanya garis tanggal kamariah Internasional di kalangan umat Islam adalah karena garis tersebut selalu berubah-ubah setiap bulan. ${ }^{57}$

Dengan demikian, karena tidak berimpitnya garis tanggal international dengan garis tanggal kalender Islam maka akan terjadi perbedaan antara tempat yang satu dan tempat yang lainnya (tergantung posisi geografisnya) dalam penggunaan kalender Islam.

\section{Aplikabilitas Pemikiran Mohammad Ilyas tentang Penyatuan Kalender Islam Inter- nasional di Indonesia}

Konsep pemikiran Mohammad Ilyas tentang upaya penyatuan kalender Islam Internasional sebagaimana telah dikemukakan pada pembahasan sebelumnya bertumpu pada dua hal pokok, yaitu konsep kriteria visibilitas hilal (crescent visibility) dan konsep Garis Tanggal Kamariah antar Bangsa atau yang populer dengan istilah International Lunar Date Line (ILDL).

Lebih jelasnya kriteria visibilitas hilal (crescent visibility) yang dikemukakan oleh Ilyas adalah sebagai berikut: (1) Beda tinggi Bulan-Matahari minimum agar hilal dapat teramati adalah $4^{\circ}$ apabila beda azimut $\mathrm{Bu}-$ lan-Matahari lebih dari $45^{\circ}$. Apabila beda azimutnya $0^{\circ}$, maka beda tinggi Bulan-Matahari harus lebih dari $10.5^{\circ},(2)$ Terbenamnya Bulan sekurang-kurangnya 41 menit lebih lambat daripada terbenamnya Matahari

57 Mohammad Ilyas, Astronomy..., hlm. 110-117. 
dan memerlukan beda waktu yang lebih besar untuk daerah yang lintangnya tinggi, (3) Hilal harus berumur lebih dari 16.5 jam bagi pengamat di daerah tropis dan lebih dari 20 jam bagi pengamat di daerah yang lintangnya lebih tinggi. ${ }^{58}$

Apabila diperhatikan lebih lanjut tentang ketentuan Ilyas tersebut, maka rukyah al-hilal, baik dengan mata telanjang maupun alat optik harus benar-benar memperhatikan faktor ketinggian hilal dan beda azimut Matahari dan Bulan. Syarat visibilitas hilal Ilyas dengan ketinggian minimal $4^{\circ}$ apabila beda azimut Matahari dan Bulan lebih dari $45^{\circ}$ menunjukkan bahwa rukyah hilal bukanlah hal yang mudah. Begitu juga apabila beda azimutnya $0^{\circ}$, maka syarat ketinggian hilal harus lebih dari $10.5^{\circ}$.

Faktor-faktor yang mempengaruhi rukyah terlalu banyak, yaitu: (a) faktor geometris (posisi Bulan-Matahari-Bumi), (b) faktor atmosferik, yaitu keadaan cuaca dan atmosfir, (c) faktor fisiologis, yaitu kemampuan mata manusia untuk menangkap pantulan sinar dari permukaan Bulan; (d) faktor psikologis, yaitu keinginan kuat untuk dapat melihat hilal sering mendorong terjadinya "halusinasi" sehingga sering terjadi klaim bahwa hilal telah terlihat padahal menurut kriteria ilmiah, bahkan dengan teropong canggih, hilal mustahil terlihat. ${ }^{59}$

Hilal dalam kriteria visibilitas hilal di sini harus didefinisikan dengan jelas. Hilal harus didefinisikan mulai dari metode sederhana rukyah tanpa alat bantu sampai dengan alat canggih hasil teknologi terbaru. Hilal juga harus terdefinisi dalam kriteria hisab yang menjelaskan hasil observasi. Hilal menurut Djamaluddin adalah "Bulan sabit pertama yang teramati di ufuk barat sesaat setelah Matahari terbenam, tampak sebagai goresan garis cahaya yang tipis, dan bila dengan menggunakan teleskop dengan pemroses citra bisa tampak sebagai garis ca-

58 Mohammad Ilyas, Astronomy ..., hlm. 97-98, dan 153.

59 Penjelasan Majelis Tarjih dan Tajdid Pimpinan Pusat Muhammadiyah Soal Penetapan Idul Fitri $1432 \mathrm{H}$ dalam www.muhammadiyah.or.id/id/ news.392, akses tanggal 20 Mei 2016. haya tipis di tepi bulatan Bulan yang mengarah ke Matahari". ${ }^{60}$

Berkaitan dengan hilal di sini perlu diperhatikan fase-fase Bulan ketika Bulan melakukan perjalanan mengelilingi Bumi. David Morrison menyebutkan ada empat fase penting bagi Bulan ${ }^{61}$, yaitu (1) Bulan baru (new moon), (2) kuartal pertama (first quarter), (3) Bulan purnama (full moon), dan (4) kuartal ketiga atau terakhir (third quarter or last quarter). ${ }^{62}$

Di antara keempat fase ini, dalam kaitannya dengan awal bulan kamariah, yang perlu dicermati adalah pada saat Bulan baru (new moon) karena pada fase inilah bulan sabit (hilal) terjadi. Fase pertama ini ditandai dengan suatu posisi di mana saat gerakan Bulan mengelilingi Bumi secara bersamaan, terdapat bagian Bulan yang terkena sinar Matahari semula sangat kecil berbentuk sabit (crescent). Bagian ini semakin hari semakin besar. Saat Bulan sabit pertama kali dapat dilihat inilah yang dinamakan hilal. ${ }^{63}$

Dari definisi tersebut dapat dipahami bahwa hilal merupakan goresan cahaya yang tipis di tepi bulatan Bulan yang mengarah ke Matahari sehingga sangatlah sulit untuk dilihat (dirukyah) oleh mata manusia, apalagi kondisi cuaca pada saat itu berawan, dan juga terdapat gangguan-gangguan lain, seperti hamburan partikel-partikel debu di langit, dan cahaya planet lain (misalnya planet Venus).

Oleh karena hilal yang sangat tipis tersebut, maka di kalangan umat Islam terdapat perbedaan pendapat tentang berapa derajat minimal hilal dapat dirukyah (imkan ar-rukyah). Sebagian umat Islam mengatakan $2^{\circ}$ seperti kriteria Nahdatul Ulama (NU) dan Badan Hisab Rukyat (BHR) Kementerian Agama (Kemenag) RI sampai

60 T. Djamaluddin, "Pengertian dan Perbandingan Mazhab tentang Hisab, Rukyat, dan Matla", makalah pada Musyawarah Nasional Majelis Tarjih di Padang, tanggal 1-5 Oktober 2003.

61 David Morrison dan Tobias Owen, The Planetary ..., hlm. 6-7.

62 Tono Saksono, Mengkompromikan ...., hlm. 3338.

63 Tono Saksono, Mengkompromikan ..., hlm. 33. 
saat ini. Muhammad Wardan mengemukakan bahwa para ulama ahli hisab berbeda-beda pendapat dalam masalah ini. Ada yang berpendapat $12^{\circ}$, ada yang mengatakan $7^{\circ}, 6^{\circ}, 5^{\circ}, 4^{\circ}$, dan lain-lain. ${ }^{64}$ Kriteria MABIMS (Menteri-Menteri Agama Brunei Darussalam, Indonesia, Malaysia, Singapura) menetapkan $2^{\circ}$ dengan syarat jarak elongasi Matahari dan Bulan minimal $3^{\circ}$ dan umur Bulan minimal 8 jam.

Perbedaan pendapat mengenai berapa derajat hilal dapat dilihat ini merupakan konsekuensi dari perbedaan hasil pengamatan dan penelitian yang dilakukan oleh para pakar falak dan astronomi. Di samping itu kriteria visibilitas hilal (crescent visibility), menurut Djamaluddin merupakan kajian astronomi yang terus berkembang, bukan sekedar untuk keperluan penentuan awal bulan kamariah (lunar calendar) bagi umat Islam, tetapi juga merupakan tantangan saintifik para pengamat hilal. ${ }^{65}$

Berkaitan dengan visibilitas hilal ini, terdapat dua aspek penting yang berpengaruh, yaitu kondisi fisik hilal akibat iluminasi (pencahayaan) pada Bulan dan kondisi cahaya latar depan akibat hamburan cahaya Matahari oleh atmosfir di ufuk (horizon). ${ }^{66}$ Kriteria visibilitas hilal yang lain adalah kriteria yang ditetapkan oleh ahli-ahli astronomi Muslim berdasarkan hasil Konferensi Penetapan Awal Bulan Kamariah di Istambul (Turki) pada tahun 1978. Konferensi ini menetapkan dua parameter rukyah, yaitu : (1) Jarak elongasi minimal adalah $8^{\circ}$, dan (2) Tinggi Bulan di atas ufuk minimal $5^{\circ} .{ }^{67}$

Kriteria visibilitas hilal Ilyas sebagaimana dijelaskan tersebut di atas, menurut penulis sangat sulit diterapkan di Indonesia. Hal ini disebabkan kriteria visibilitas hilal (imkan ar-rukyah) di Indonesia sampai saat ini, sebagaimana yang dipakai oleh Ke-

64 Muhammad Wardan, Hisab 'Urfi dan Hakiki, (Yogyakarta: Siaran, 1957), hlm. 43.

65 Thomas Djamaluddin, Astronomi Memberi Solusi Penyatuan Ummat, (Jakarta: LAPAN, 2011), hlm. 12-13.

66 Thomas Djamaluddin, Astronomi ..., hlm. 13.

67 Syamsul Anwar, Interkoneksi...., hlm. 60. menterian AgamaRepublik Indonesia adalah minimal $2^{\circ}$. Hal ini berarti akan tetap terjadi perbedaan tanggal dalam memulai bulan baru kamariah apabila kondisi hilal di Indonesia dalam perhitungan hisab berada pada ketinggian sekitar $2^{\circ}$.

Garis Tanggal Kamariah antar Bangsa (International Lunar Date Line) yang digagas Ilyas juga selalu berubah-ubah setiap bulan. Hal ini akan mengakibatkan perbedaan hari dalam kalender hijriyah apabila dalam suatu negara tersebut dilewati garis tanggal tersebut, sehingga apabila di Indonesia dilewati Garis Tanggal Kamariah Internasional sebagaimana yang digagas oleh Ilyas, maka tidak menutup kemungkinan akan terjadi perbedaan hari dalam memulai tanggal baru bulan kamariah.

Hal ini dapat terjadi dikarenakan batas hari juga bergerak mengikuti perpindahan garis tanggal kamariah baru ke arah barat, maka hal ini akan mengakibatkan hari (syar'i) terakhir bulan berjalan pada kawasan yang terletak antara garis tanggal kamariah lama dan garis tanggal kamariah baru harus diperpanjang sehingga hari syar'i itu menjadi 48 jam, tidak lagi 24 jam. Dengan kata lain, hari yang sama harus diulang dua kali, misalnya apabila hari terakhir bulan berjalan adalah hari Selasa, maka hari Selasa itu akan terjadi $2 \times 24$ jam (dua hari berturut-turut). Hal ini terjadi karena batas hari (garis tanggal) bergeser ke Barat di mana semestinya hari Selasa itu sudah berakhir pada garis tanggal yang lama, namun tidak jadi berakhir karena menanti sampainya ke garis tanggal yang baru. Apabila telah sampai pada garis tanggal yang baru, maka tanggal 1 bulan baru dimulai bersamaan dengan dimulainya hari baru, yakni hari Rabu (syar'i), meskipun hari menurut definisi Garis Tanggal Internasional (Syamsiyah) telah berganti sejak dari posisi $180^{\circ} .{ }^{68}$

Di samping problem kriteria visibilitas hilal yang berbeda antara Kementerian Agama RI dan kriteria Ilyas, dan juga Garis Tanggal Kamariah Antar Bangsa (Interna-

68 Syamsul Anwar, Interkoneksi ..., hlm. 110. 
tional Lunar Date Line) yang berubah-ubah setiap bulan, persoalan lain yang menjadikan konsep pemikiran Mohammad Ilyas tentang Kalender Islam Internasional sulit diterapkan di Indonesia adalah perbedaan metode dan kriteria yang digunakan oleh masing-masing ormas Islam di Indonesia.

\section{KESIMPULAN}

Konsep pemikiran Mohammad Ilyas tentang Kalender Islam Internasional bertumpu pada hisab imkan ar-rukyah (visibilitas hilal) dan Garis Tanggal Kamariah Antar Bangsa (International Lunar Date Line). Kriteria visibilitas hilal Ilyas menggunakan kombinasi dua parameter, yaitu parameter ketinggian relatif geosentrik (geocentric relative altitude) dan azimut relatif (relative azimut). Kriteria visibilitas hilal yang dikemukakan oleh Ilyas adalah: (1) Beda tinggi Bulan-Matahari minimum agar hilal dapat teramati adalah $4^{\circ}$ apabila beda azimut Bulan-Matahari lebih dari $45^{\circ}$. Apabila beda azimutn- ya $0^{\circ}$, maka beda tinggi Bulan-Matahari harus lebih dari $10.5^{\circ}$, (2) Terbenamnya Bulan sekurang-kurangnya 41 menit lebih lambat daripada terbenamnya Matahari dan memerlukan beda waktu yang lebih besar untuk daerah yang lintangnya tinggi, (3) Hilal harus berumur lebih dari 16.5 jam bagi pengamat di daerah tropis dan lebih dari 20 jam bagi pengamat di daerah yang lintangnya lebih tinggi.

Aplikabilitas pemikiran Mohammad Ilyas tentang kriteria visibilitas hilal (crescent visibility/imkan ar-rukyah) sebagai upaya penyatuan kalender Islam Internasional sampai saat ini belum dapat diterima oleh umat Islam di Indonesia. Hal ini disebabkan perbedaan kriteria visibilitas hilal yang dipakai oleh umat Islam di Indonesia (Kementerian Agama RI) dengan kriteria Ilyas. Garis Tanggal Kamariah Antar Bangsa (International Lunar Date Line) yang digagas Ilyas juga selalu berubah-ubah setiap bulan sehingga seringkali menimbulkan perbedaan hari dalam memulai bulan baru di suatu daerah atau negara. Wallahu A Iam.

\section{DAFTAR PUSTAKA}

Anwar, Syamsul, 2011, Interkoneksi Studi Hadis dan Astronomi, Yogyakarta: Suara Muhammadiyah.

Azhari, Susiknan, 2004, Ilmu Falak:Teori dan Praktek, Yogyakarta: Suara Muhammadiyah. , 2007, Ilmu Falak (Perjumpaan Khazanah Islam dan Sains Modern), Yogyakarta: Suara Muhammadiyah.

2007, Hisab dan Rukyat (Wacana Untuk Membangun Kebersamaan di Tengah Perbedaan), Yogyakarta: Pustaka Pelajar.

, 2008, Ensiklopedi Hisab Rukyat, Yogyakarta: Pustaka Pelajar.

Darsono, Ruswa, 2010, Penanggalan Islam (Tinjauan Sistem, Fiqh, dan Hisab), Yogyakarta: Labda Press.

Departemen Agama RI, t.t., Almanak Hisab Rukyat, Jakarta : Proyek Pembinaan Badan Peradilan Agama Islam.

Djamaluddin, T., 2005, Menggagas Fiqih Astronomis (Telaah Hisab Rukyah dan Pencarian Solusi Perbedaan Hari Raya), Bandung: Kaki Langit.

, Thomas, 2011, Astronomi Memberi Solusi Penyatuan Ummat, Jakarta: LAPAN.

Djambek, Sa'adoeddin, 1976, Hisab Awal Bulan, Jakarta: Tinta Mas. 
Ibn Kasir, Abi al-Fida' Isma'il, t.t., Tafsir al-Qur'an al-'Azim, Juz I, Beirut: Dar al-Fikr al-'Arabi.

Ilyas, Mohammad, 1984, A Modern Guide to Astronomical Calculation of Islamic Calendar, Times and Qibla, Kuala Lumpur: Berita Publishing.

, 1997, Astronomy of Islamic Calendar, Kuala Lumpur: A.S. Noordeen.

, 1997, Sistem Kalender Islam dari Perspektif Astronomi, Kuala Lumpur : Dewan Bahasa dan Pustaka.

Kamaluddin, Husein, 1979, Ta'yin Awa'ili asy Syuhur al-'Arabiyyah bi al-Isti'mal al-Hisab, Jeddah: Dar al-Nasyr.

Khazin, Muhyiddin, 2008, Ilmu Falak dalam Teori dan Praktek, Yogyakarta: Buana Pustaka.

Majelis Tarjih dan Tajdid Pimpinan Pusat Muhammadiyah, 2009, Pedoman Hisab Muhammadiyah,Cetakan Kedua, Yogyakarta: Majelis Tarjih dan Tajdid PP Muhammadiyah.

Maragi, Ahmad Mustafa, t.t., Tafsir al-Maragi, Juz II, Beirut: Dar al-Fikr.

Morrison, David dan Tobias Owen, 1940, The Planetary System, New York: Addison-Wesley Publishing.

Rasyid Rida, Muhammad, 1999, Tafsir Al-Manar, Jilid XI, Beirut: Dar al-Kutub al-'Ilmiyah. , 2005, Tafsir Al-Manar, Jilid II, Beirut: Dar al-Kutub al-`Ilmiyah.

Saksono, Tono, 2007, Mengkompromikan Rukyat dan Hisab, Jakarta: Amythias Publicita bekerja sama dengan Center for Islamic Studies.

Shihab, M. Quraish, 2007, Tafsir al-Misbah, Juz I, Jakarta: Lentera Hati.

Wardan, Muhammad, 1957, Hisab 'Urfi dan Hakiki, Jogjakarta: Siaran.

Zuhaili, Wahbah, t.t., At-Tafsir al-Munir fi al-'Aqidah wa asy-Syari'ah wa al-Manhaj, Juz II dan XXIII, Beirut: Dar al-Fikr.

\section{Makalah:}

Anwar, Syamsul, (2008), “Perkembangan Pemikiran tentang Kalender Islam Internasional", Makalah pada Musyawarah Nasional Ahli Hisab dan Fikih Muhammadiyah pada tanggal 21-22 Jumadal Saniyah 1429 H/25-26 Juni 2008 M di Yogyakarta.

Djamaluddin, T., (2003), "Pengertian dan Perbandingan Mazhab tentang Hisab, Rukyat, dan Matla'", makalah pada Musyawarah Nasional Majelis Tarjih di Padang, tanggal 1-5 Oktober 2003.

, (2010), “Redefinisi Hilal Menuju Titik Temu Kalender Hijriyah”, makalah pada Seminar Kelas Program Doktor Ilmu Falak Pascasarjana IAIN Walisongo.

, (2009), Materi Kuliah Fikh Hisab Rukyah, Program Doktor Hukum Islam Konsentrasi Ilmu Falak IAIN Walisongo.

\section{Website:}

www.muhammadiyah.or.id./id.news.392. 